\title{
«Rome n'est plus dans Rome»? Entre mythe et satire. La représentation de Rome en France au tournant des XVII et $\mathrm{XVIII}^{e}$ siècles
}

\section{Monica Pavesio}

\section{OpenEdition}

\section{Journals}

\section{Edizione digitale}

URL: https://journals.openedition.org/studifrancesi/11499

DOI: 10.4000/studifrancesi. 11499

ISSN: 2421-5856

\section{Editore}

Rosenberg \& Sellier

\section{Edizione cartacea}

Data di pubblicazione: 1 avril 2018

Paginazione: 128-129

ISSN: 0039-2944

Notizia bibliografica digitale

Monica Pavesio, ««Rome n'est plus dans Rome»? Entre mythe et satire. La représentation de Rome en France au tournant des XVII et XVIII siècles», Studi Francesi [Online], 184 (LXII | I) | 2018, online dal 02 juillet 2018, consultato il 15 novembre 2021. URL: http://journals.openedition.org/studifrancesi/11499 ; DOI: https://doi.org/10.4000/studifrancesi.11499

Questo documento è stato generato automaticamente il 15 novembre 2021.

\section{(c) (i) (9)}

Studi Francesi è distribuita con Licenza Creative Commons Attribuzione - Non commerciale - Non opere derivate 4.0 Internazionale. 


\title{
«Rome n'est plus dans Rome»? Entre mythe et satire. La représentation de Rome en France au tournant des XVII et XVIII siècles
}

\author{
Monica Pavesio
}

\section{NOTIZIA}

«Rome n'est plus dans Rome»? Entre mythe et satire. La représentation de Rome en France au tournant des XVII et XVIII ${ }^{e}$ siècles, Actes du colloque international de Rome (8-10 mars 2012), publiés par G. FERREYROLLES et L. NORCI CAGIANO DE AZEVEDO, Paris, Champion, 2015, $255 \mathrm{pp}$.

1 Il convegno, svoltosi a Roma nel 2012, grazie alla convenzione di cooperazione tra le università di Paris-Sorbonne e di Roma Tre, ha riunito specialisti italiani e francesi per analizzare l'immagine di Roma in Francia nel periodo a cavallo tra il XVII e il XVIII secolo. Come si evince dalle introduzioni di G. FERREYROLLES (pp. 9-10) e di F. WAQUET (pp. 11-19) agli atti pubblicati presso Champion nel 2015, il periodo preso in esame dagli organizzatori rappresenta il momento in cui il modello romano entra in crisi in tutti i campi del sapere. La celebre formula pronunciata nel Sertorius di Corneille del 1662, utilizzata come titolo del convegno, traduce una serie di interrogativi e di opposizioni tra una città reale e una ideale, tra una Roma vera e una falsa, che illustrano come il mito della città eterna sia diffuso in tutta la cultura europea. Negli anni che vanno dal 1662 al 1729, lo sguardo dei francesi sulla città cambia e l'immagine di Roma vacilla, perché la Francia rivendica per se stessa il ruolo di modello che fino a quel momento aveva riconosciuto all'Italia.

2 Le comunicazioni sono state suddivise in quattro gruppi: la prima parte riguarda la Roma pontificia, capitale della cristianità; la seconda riunisce gli studi su Roma come 
soggetto drammatico e romanzesco; la terza è consacrata alla messa in crisi del paradigma romano; la quarta, infine, è dedicata all'utilizzo letterario dei grandi personaggi della storia romana.

3 Nel primo gruppo di saggi, il lavoro di н. michon, L'Église chez François de Sales: de la controverse à la spiritualité (pp. 23-34) dimostra come François de Sales ripensi nei suoi scritti alla nozione di "Chiesa" e alla funzione del papato, dopo la Riforma e il Concilio di Trento; quello di F.X. cucHE, Claude Fleury et la Rome des Papes du Moyen Âge (pp. 35-56), analizza gli scritti storici dell'avvocato Fleury, soffermandosi in particolare sulla sua Histoire ecclésiastique, esempio della polemica antiromana, sviluppatasi in Francia nel periodo esaminato; S. MENANT, nel suo La satire romaine dans la querelle de l'“Unigenitus" (pp. 57-71) studia le pièces satiriche pubblicate in Francia, dopo la diffusione della bolla papale, esempi anch'esse della forte opposizione dei francesi alla politica papale; $\mathrm{s}$. ANDREATTA dimostra che i legami fra la Francia e Roma si degradano durante il pontificato di Clemente XI, originando l'usura del mito romano (Le pontificat de Clément XI et la monarchie française, pp. 73-91).

4 Nel secondo gruppo di contributi, L. RESCIA in Vrais et faux Romains à l'épreuve de la dramaturgie cornelienne (pp. 95-112), analizza il concetto di vera e falsa romanità nel Sertorius, verificando come le fonti storiche sono assoggettate all'efficacia drammaturgica, per poi allargare il discorso alla dialettica del vero e del falso, che si ritrova nelle tragedie romane della maturità, ma anche nella prima grande tragedia storica corneliana dedicata a Roma, Horace; A. BERETTA ANGUISSOLA (La Rome bipolare de Racine, pp. 113-125) si occupa invece della Roma bipolare, città santa e nuova Sodoma, mito positivo e negativo, nelle tragedie di Racine Britannicus, Bérénice e Mithridate; v. POMPEJANo ("Les Exilés de la Cour d'Auguste" ou la romanité galante de Mme de Villedieu, pp. 127-141), infine, analizza il romanzo di Mme de Villedieu, Les Exilés de la cour d'Auguste, una delle ultime rappresentazioni francesi della Roma imperiale, alla luce dell'evoluzione del genere della novella storica e della diffusione della galanterie.

La terza parte degli atti è consacrata alla messa in crisi del paradigma romano. D. REGUIG ("Quid Romae faciam?»: la satire comme lieu poétique chez Boileau, pp. 145-159) analizza come Boileau utilizzi le satire di Giovenale, ma superi il modello ed arrivi a specializzare il genere della satira nell'ambito della critica poetica; B. GUION (L'image de Rome dans la Querelle: la remise en cause du modèle romain chez les Modernes, pp. 161-180) illustra come la contestazione del modello romano sia uno dei cavalli di battaglia dei Modernes nella famosa Querelle che li vide contrapposti agli Anciens; B. NORCI CAGIANO (Montesquieu à Rome et la leçon de Borromini, pp. 181-197) ci presenta Montesquieu, dopo il suo viaggio a Roma, come un ammiratore della Roma barocca di Borromini e Bernini e contestatore della Roma antica.

6 Nella quarta e ultima sezione, gli studiosi si sono concentrati sull'utilizzo letterario dei personaggi della storia romana. Nei Dialogues des morts di Fontenelle, analizzati da B. PIQUÉ (Les «dames romaines» dans les "Nouveaux Dialogues des morts" de Fontenelle, pp. 201-212) le "dames romaines» rappresentate non sono più esempi di virtù, ma portaparola dell'eros libertino; nei Dialogues des morts di Fénelon, studiati da B. PAPASOGLI (Rome dans l'au-delà: les personnages romains des "Dialogues des morts" de Fénelon, pp. 213226), i personaggi romani, rappresentati come eroi negativi, permettono all'autore la critica delle guerre di conquista, delle ambizioni d'egemonia e del lusso del tempo presente; J.C. BONNET, nell'ultimo saggio (Le thème romain chez Montesquieu et ses échos dans 
les siècles, pp. 227-236) definisce l'influenza che gli scritti sulla decadenza romana di Montesquieu hanno avuto sugli scrittori francesi della metà del xvIII secolo.

7 Nella conclusione (pp. 237-239), G. GIORGI illustra i temi del convegno. In tutti i testi analizzati, la rappresentazione della città non è mai neutra, oscilla tra mito e satira, tra ammirazione e disprezzo, ma la distruzione del paradigma romano in Francia nel periodo esaminato è sintomatica del fascino che la città eterna ha suscitato e continua a suscitare, anche nel periodo di maggior affermazione di Parigi e della Francia a livello europeo. 